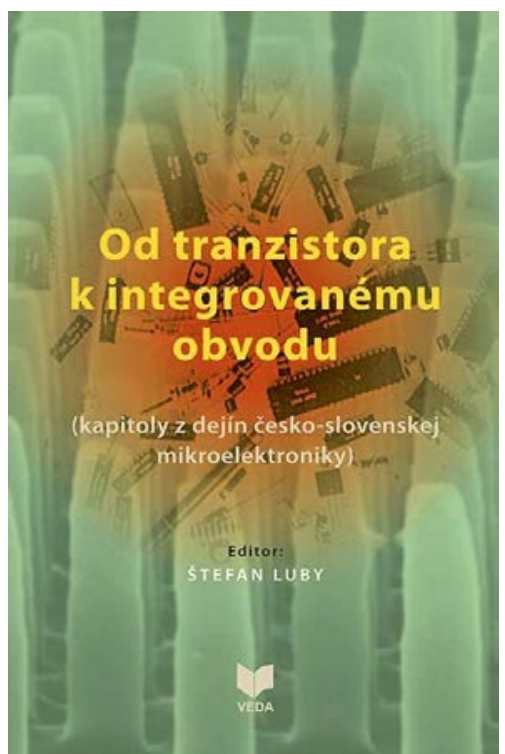

\section{From Transistor to Integrated Circuit}

\author{
Štefan Luby, Július Krempaský, \\ Rudolf Kinder, Vladimír Áč, Milan Ožvold, \\ Jozef Novák, Ivo Vávra, Peter Lobotka, \\ Ivan Kostič, Martin Šperka, Daniel Donoval
}

Although concerning mostly the middle European region, it may be of interest for a wider reading public. A book telling the story of recent history in research and development in electrical and namely electronic engineering has appeared. For more than forty years after the world war second, due to geopolitical situation there were at least two streams, not only in social sphere, but also in technology development. East and West; a kind of competition. Someone may tend to talk about the "Eastern Silicon Valley". Without exalting, they were striving for and reached noticeable results too, also in former Czechoslovakia.

Authors working in former industrial development, and at institutions of Slovak Academy of Sciences and Slovak University of Technology present on about 220 pages, an interesting contribution concerning the historical background of the contemporary knowledge comprising several technological branches. The book is enriched by quite an amount of original photographic material and contains a comprehensive list of worldwide literature sources concerning the described matters. English summaries are appended also at the end.

It starts with a short historical review of semiconductors devolvement after the most important invention of the 20th Century - discovery of the transistor, later presented with the Nobel Prize in Physics (1956). This introductory part, written by Š. Luby - renowned scientist and former president of Slovak Academy of Sciences, gives the reader an outline from about 1945 semiconductor up to the present achievements in nano-technology.

J. Krempaský, the Slovak nestor of semiconductor physics shares his reminiscences since 1953, preceding the R. Kinder's personal memories of another leading scientist in semiconductor technology in former Czechoslovakia Helmar Frank, a man of several citizenship during his life, and well known also abroad.

Vladimír Áč presents a comprehensive and wider insight on microelectronics in Slovakia not only from the industrial point of view, and the development and batch production of CCD camera in Czechoslovakia by Tesla Piešt'any following firstly produced transistors, and unipolar integrated circuits. This is completed by M. Ožvold contribution about CCD chips developed and produced in Slovakia in eighties.

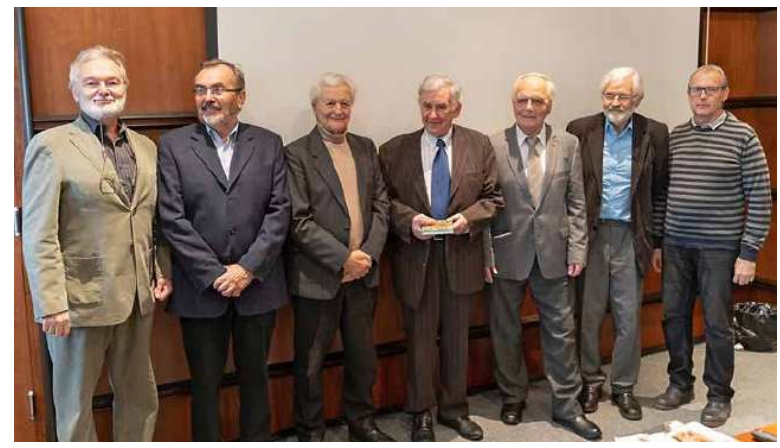

Some of authors: P. Lobotka, I. Vávra, J. Krempaský, Š. Luby, V. Áč, M. Šperka and I. Kostič

Ivan Kostič is describing development and successful utilization of lithography in the country, that has also reached the internationally recognized level. Martin Šperka and Daniel Donoval contributed by chapters about microelectronic applications in computing and about preparing the graduates for technology and research by Faculty of Electronics a Informatics at Slovak Univesity of Technology. Additionally, parts written by Peter Lobotka, Jozef Novák, and Ivo Vávra help to complete the whole image of scientific and technological scene in past and recent time.

The book ends up with a list of Nobel Prize laureates in semiconductor physics and technology, and terminological vocabulary followed by explaining the commonly used abbreviations.

Book review by $M$. Kollár 